\title{
The Analysis of Efficiency of Acoustic Emission Diagnostic Method for the Determination of Defect Coordinates
}

\author{
Aleksandrs Urbahs ${ }^{1}$, Aija Valberga ${ }^{2}$, Muharbijs Banovs $^{3}$, Kristine Carjova $^{4}$, Ilze Stelpa ${ }^{5}$ \\ ${ }^{1-5}$ Institute of Aeronautics, Faculty of Transport and Mechanical Engineering, Riga Technical University
}

\begin{abstract}
Acoustic emission (AE) method is widely used as a non-destructive control tool of vehicle points and construction and also as a tool for technical condition monitoring. One of the most important AE diagnostic technological operations is the determination of $\mathrm{AE}$ source defect coordinates. Modern defect location techniques allow detecting coordinates of developing defects with high accuracy and reliability. There are several AE source detection methods, but the most popular one is a signal arrival time difference method.
\end{abstract}

Keywords - Acoustic emission, defect coordinates, diagnosis.

\section{INTRODUCTION}

One of the most perspective methods for evaluating the technical condition of industrial objects, such as vehicles, pipelines, reservoirs, is the acoustic emission (AE) method [1] - [6]. Acoustic emission is the radiation process of elastic waves caused by the local dynamic restructuring of the internal structure of the material. AE is a passive method of non-destructive inspection method, because the elastic oscillation source is an object that emits as a result of its external effects, such as mechanical loads, pressure, temperature changes.

$\mathrm{AE}$ method in comparison with other non-destructive test and diagnostic methods has a number of advantages, including the possibility of controlling small as well as bulky items throughout the volume of production, test and operation process. The given method allows keeping track of defects in real-time without interrupting the resource tests. The main advantage of this method is the high susceptibility to the development of existing defects.

During the control process using AE method, a control object is in the loaded condition. Crack or other defect that develops in the loaded object emits acoustic waves that are recorded with the help of acoustic emission converter (AEC) 1 (see Fig. 1). Afterwards, AE signal is strengthened by preamplifier 2 , but noise is filtered by filter 3 . The signal is again reinforced in main amplifier 4 and converted from analogue to digital format in order to further process the required data in signal processing block 5 and in determination block of source location 6 .

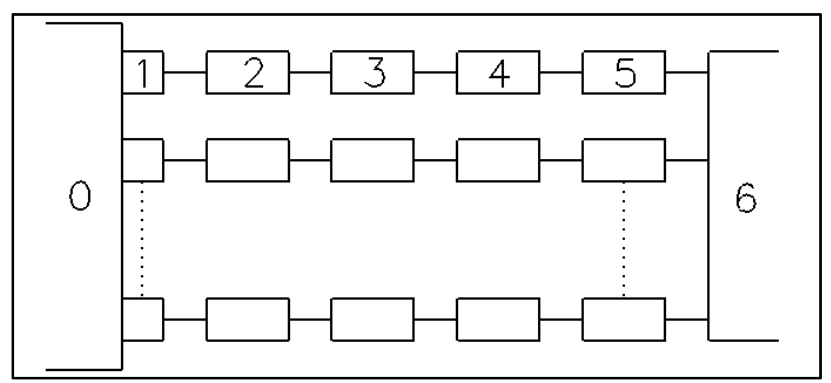

Fig. 1. Multichannel AE hardware functional diagram: 0 - control object, 1 converter, 2 - preamplifier, 3 - filter, 4 - main amplifier, 5 - acquisition system (signal processing block), 6 - determination block of source location (coordinates).

Determination or localization of $\mathrm{AE}$ source coordinates is one of the most important technological AE diagnostic operations. Determination of coordinates is defined in a plane without detecting the depth of material defect of the controlled object. When determining the AE signals that come to several AE converters, it is possible to determine the parameters of the source coordinates. For this purpose, the signal arrival time and amplitude are used. Values of the above-mentioned factors vary depending on the distance between the defect and AEC.

In practice, time difference of arrival (TDOA) methods are frequently applied. These methods include linear, planar and spatial location, as well as regional detection methods [7]. Two methods for the detection of continuous AE (continuous emission can be characterised by a low amplitude and high signal frequency) sources are used:

1. cross-correlation function-based method;

2. method, where attenuation is evaluated.

\section{Defect Detection Methods of Acoustic EMission}

\section{A. Acoustic Emission Defect Coordinates Using TDOA Method}

The most common AE source localization is performed by a signal arrival time difference method, where the signal arrival time is determined by the maximum amplitude or reaching a threshold.

In linear objects such as tubes, pipes or bars, fault location can best be determined by a linear localization method. Linear localization method requires two AE converters (AECs): if the defect is located midway between the two converters, arrival time difference $\Delta t=0$, while if the defect is closer to any 
converter, $\Delta t=2 \Delta l / c$, where $\Delta l-$ the source of deviation in relation to the centre point, $c$ - the speed of ultrasound in the object. In this case, $c$ is a certain value, while $\Delta l$ is determined during control; thereby it is possible to determine coordinates of the object with respect to a line central point joining two AECs.

The plane has been examined on which there are 2 AECs at a given distance $\Delta d_{1,2}$. TDOA signal to these AECs is registered and known $-\Delta d_{1,2}$. Knowing the oscillation propagation velocity of this material, the hyperbole, on which there is a defect, can be determined. Working with three AECs, the source will be on the intersection of two hyperboles; each is fixed to its AEC pair.

Time difference of arrival for the first and second AEC pairs can be expressed as follows:

$\Delta t_{1,2}=t_{2}-t_{1}=\frac{\Delta d_{1,2}}{c}=\frac{\sqrt{\left(x-x_{2}\right)^{2}+\left(y-y_{2}\right)^{2}}-\sqrt{\left(x-x_{1}\right)^{2}+\left(y-y_{1}\right)^{2}}}{c}$

where $\left(x_{1}, y_{1}\right)$ - the first AEC coordinates; $\left(x_{2}, y_{2}\right)$ - the second AEC coordinates; $(x, y)$ - object coordinates; $c$ - the speed of ultrasound in the object; $\Delta d_{1,2}-$ the distance between the first and second AEC.

Time difference of arrival for the first and third AEC pairs is expressed in the same way; therefore, there are only two unknown values $x$ and $y$ in the equation and they can be easily calculated.

In cases, when the material is anisotropic, defect localization becomes more difficult [7] - [9] because the oscillation propagation speed becomes dependent on the direction defined by angle $\theta$. Consequently, for this case (1) looks like this:

$\Delta t_{1,2}=t_{2}-t_{1}=\frac{d_{2}}{v_{2}}-\frac{d_{1}}{v_{1}}=$

$=\frac{\sqrt{\left(x-x_{2}\right)^{2}+\left(y-y_{2}\right)^{2}}}{v_{2}}-\frac{\sqrt{\left(x-x_{1}\right)^{2}+\left(y-y_{1}\right)^{2}}}{v_{1}}$,

where $d_{i}$ - the distance to a converter; $i, v_{i}$ - the speed of ultrasound in a particular direction with a direction vector

$\tan \left(\theta_{i}\right)=\frac{\left(y-y_{i}\right)}{\left(x-x_{i}\right)}$

Thus, it is necessary to have three AECs in order to determine AE source coordinates on the plane. However, in practice four or more AECs are often used to reduce methodological errors of the coordinates. [10]

Equilateral triangle-centred scheme [11] is more often used for AEC placement (see Fig. 2). By applying this scheme, the source coordinates can be determined using expressions that are given in [12]:

$$
\begin{aligned}
& x=\left(r_{3}-r_{1}\right)\left(2 R+r_{2}+r_{3}\right) / 2 B \sqrt{3} ; \\
& y=B^{2}-r_{1}\left(2 R+r_{1}\right) / 2 B ; \\
& R=\left(3 B^{2}-r_{1}^{2}-r_{2}^{2}-r_{3}^{2}\right) / 2\left(r_{1}-r_{2}-r_{3}\right),
\end{aligned}
$$

where $B$ - the distance between central and peripheral converters; $x$ and $y$ - AE signal source coordinates; $\mathrm{R}-$ the distance between source and central converters; $r_{i}=\Delta t_{i} ; \Delta t_{i}$ the time difference of arrival on peripheral converters in relation to central AEC; $c$ - the speed of ultrasound in the object.

It should be noted that in cases where the defect is outside the triangle, there is a huge increase in the coordinates of a position error that otherwise would not exceed $\Delta R / B<0.1$ [13].

Usually, a coordinate network [14] is created before the registration (see Fig. 3). In this network, the time difference of arrival for each point is calculated. Theoretical values are compared to the ones obtained in practice after logging $\mathrm{AE}$ source signals. The point, at which there is the lowest square sum of theoretical and the real TDOA, is taken as the real location of AE signal source:

$\Omega=\min \left(\sum_{\substack{i=1 \rightarrow 4 \\ j=i+1 \rightarrow 4}}\left[\Delta t_{i, j}^{a p r}\left(x_{n}^{a p r}, y_{n}^{a p r}\right)-\Delta t_{i, j}\left(x_{r}, y_{r}\right)\right]^{2}\right)(7)$

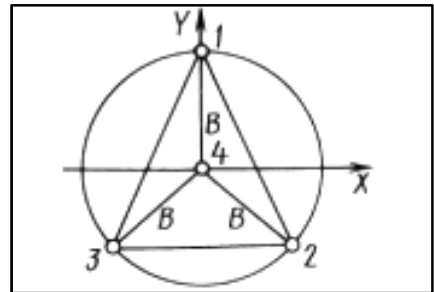

Fig. 2. Equilateral triangle-centred scheme for AEC placement.

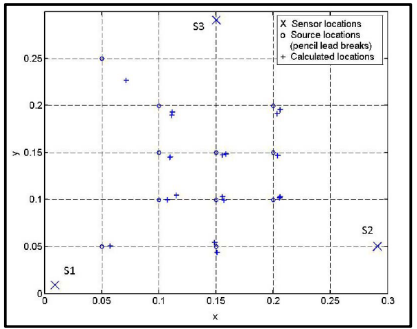

Fig. 3. Coordinates network with coordinates of sensors, real and theoretical sources.

Coordinates of spatial objects are analogous to (1) and (7):

$$
\begin{gathered}
\Delta t_{1,2}=\frac{\sqrt{\left(x-x_{2}\right)^{2}+\left(y-y_{2}\right)^{2}+\left(z-z_{2}\right)^{2}}}{c}- \\
-\frac{-\sqrt{\left(x-x_{1}\right)^{2}+\left(y-y_{1}\right)^{2}+\left(z-z_{1}\right)^{2}}}{c} \\
\Omega= \\
\min \left(\sum_{\substack{i=1 \rightarrow 4 \\
j=i+1 \rightarrow 4}}\left[\Delta t_{i, j}^{a p r}\left(x_{n}^{a p r}, y_{n}^{a p r}, z_{n}^{a p r}\right)-\Delta t_{i, j}\left(x_{r}, y_{r}, z_{r}\right)\right]^{2}\right)
\end{gathered}
$$

\section{B. Zone Location}

Zone detection method [11] is based on the principle that AEC, which has registered the highest signal power or 
amplitude value, is the most closest to the AE source. This method has the minimum amount of information, because it allows identifying a zone rather than a specific point, in which a defect occurs (Fig. 4). By using the higher number of AECs it is possible to determine the sequence of arrival of a signal to them, thus increasing the detection accuracy.

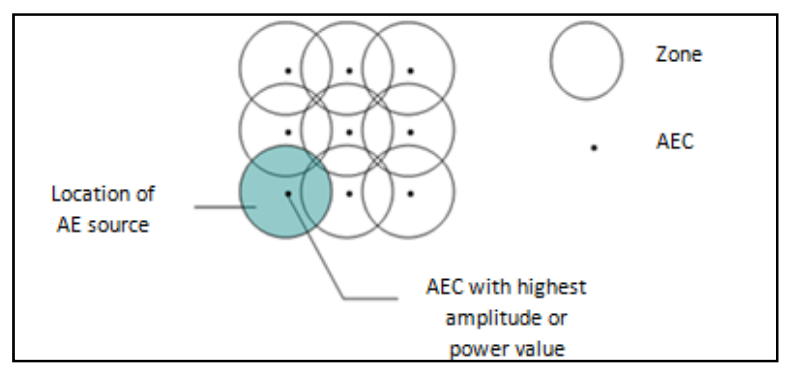

Fig. 4. Zone location.

\section{ACOUSTIC EMISSION HARDWARE AND SOFTWARE}

Acoustic emission hardware is characterised by the need to work in a relatively large dynamic range, which is due to the fact that it is very important to discover single small amplitude of AE signals, as well as recording AE signals during crack acceleration development process, which is characterised by an intense high amplitude impulse flow.

Acoustic emission hardware consists of the following assemblies:

- AE converters (AECs), the number of which depends on the chosen localization methods;

- preamplifiers and main amplifiers;

- $\quad$ signal identification and processing equipment, including threshold equipment, AE signal extraction and

measurement equipment, data recording and presentation equipment;

- additional parameter measuring instruments;

- controllers.

Waveform and spectrum unification in clusters is carried out after the recording of AE signals. Clusters, unifying number of signals correspond to an event or defect. Different statistical methods use AE signal clustering in order to prevent the possibility of combining different event-driven signals in the same cluster.

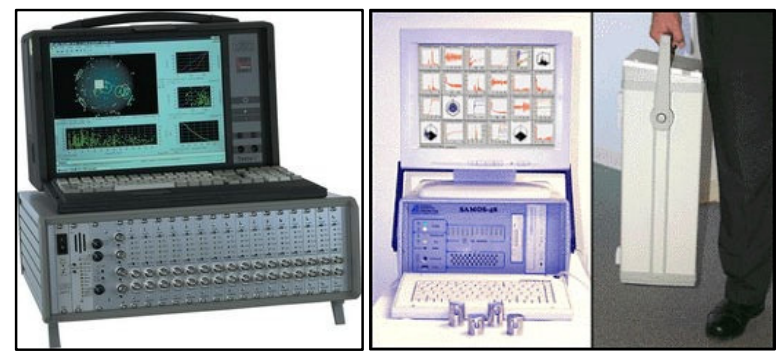

Fig. 5. General use of AE equipment.

After processing AE signals proceed to the display, where the object expansion corresponding to the surface of the object and the converter arrangement can be seen. This type of signal is shown in Fig. 6 [5]. To assess the defect risk level, sources are classified according to amplitude, integrated or local dynamic criteria. Classified defects according to their degree of danger are shown in different colours, so it is possible to locate on the map not only the fault location of the object, but also the degree of risk involved, thus making it possible to objectively determine the defect impact on the control object capacity.

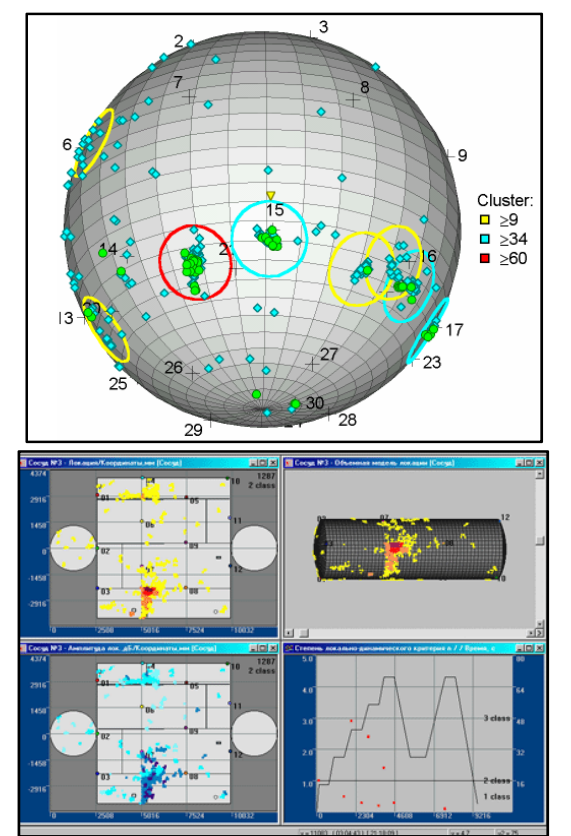

Fig. 6. Display of AE equipment with information and defect localization depiction.

In recent decades, localization methods have evolved rapidly due to high-speed hardware capabilities. Today, the coordinates of the source position error usually constitute 3$5 \%$ of the maximum distance between converters, but not less than the wall thickness of the controlled object. The last aspect is related to the fact that the location of source on a controlled object layer is not determined; the subject of research is epicentre of source of the epicentre on the object surface.

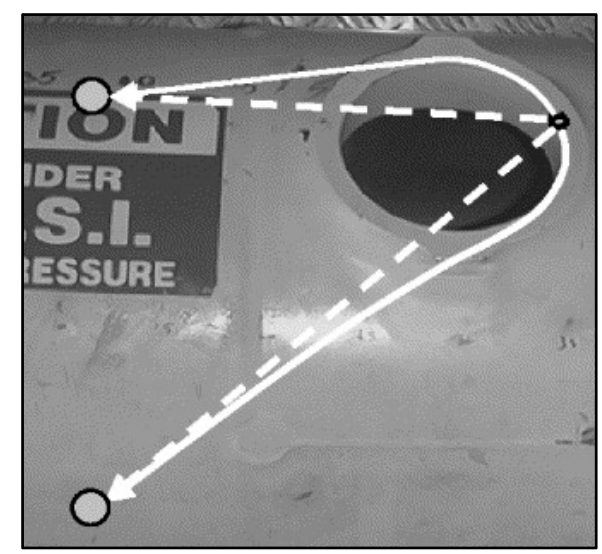

Fig. 7. Real (continuous line) and theoretical (dashed line) emission trajectory of waves. 
Coordinate calculation error is determined by the time difference of signal arrival (TDOA) measurement errors. There may be many sources of error, for example:

- improper determination of sound propagation speed in the object;

- incorrect determination of the coordinates of the AEC, which is a laborious process. One of the possible ways to prevent these errors is the automation of AEP coordinates, which is offered in [6];

- time interval error that depends on the signal structure, its forefront growth in nature, noise level, etc.;

- actual propagation path mismatch, as shown in Fig. 7. [16];

- $\quad$ signal propagation velocity anisotropy existence;

- changes in signal shape during spreading in a structure;

- $\quad$ signal overlapping, as well as multi-source simultaneous operation;

- different types of waves, which spread at different speeds, login with converters.

Despite rapid development of localization methods by $\mathrm{AE}$ method, their application is difficult because of the acoustic wave reflection, transformation, decay, and other factors.

When solving defect localization tasks in real time, a range of tasks has to be solved, e.g., signal decoding, signal detection misconceptions, AE informative parameters for specific design and specific loading conditions. It should be noted that the loading equipment also transmits acoustic noise, and the amplitude and spectrum are identical in the fault signals. Future research is aimed at specific localization algorithm development for individual structures and units in order to increase the localization accuracy.

\section{CONCLUSIONS}

The article has examined the capability of defect coordinate localization by means of acoustic emission method. Time difference of arrival (linear, planar, and spatial) and zone detection methods, as well as the main sources of measurement error have been considered. As far as multichannel acoustic emission hardware options are concerned, it has been concluded that the defect tracking error ranges from $3 \%$ to $5 \%$.

The currently used AE tracking methods are generalized and cannot be used for the control of any object. Consequently, further research in this area will be devoted to the development of algorithm specific products for diagnostic purposes.

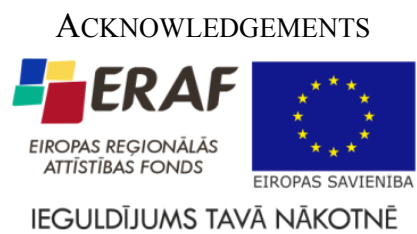

The research has been supported by the European Regional Development Fund within the project "Development of an Unmanned Aircraft System and Creation of the Industrial Prototypes of Unmanned Aerial Vehicles for Performing the Tasks of Latvian National Economy".

No.2010/0256/2DP/2.1.1.1.0/10/APIA/VIAA/070.

\section{REFERENCES}

[1] A. Urbahs, A. Shanyavskiy, M. Banovs, K. Carjova, Evaluation of an acoustic emission criterion of under surface fatigue cracks development mechanism in metals: 16th International Conference Transport Means, pp. 131-134, October 25-26, Kaunas, Lithuania, 2012.

[2] A. Urbach, M. Banov and V. Turko, Hypothesis of local zones with dependent fatigue damages accumulation: $3 r d$ International Conference on Mechanical and Aerospace Engineering, ICMAE 2012, pp. 19-23, July 7-8, Paris, France, 2012.

[3] A. Urbach, M. Banov, Y. Harbuz, Y. Feschuk, and Y. Sologubov, Evaluations of degree of damage and probability of forecasting of destructing load in anisotropic composites by means of acoustic emission in materials under static loading: 15th International Conference Transport Means, pp. 270-273, October 20-21, Kaunas, Lithuania, 2011.

[4] M. Banov, A. Urbakh, R. Tukhtiev, A. Malyshev, "Method of determing coordinates of signal resources of Acoustic emission," USSR Patent, SU1516964, October 23, 1989

[5] C. Hellier, Handbook of Non-destructive Evaluation. MacGraw-Hill Professional, 2001.

[6] D. A. Terentev, "Avtomaticeskoe opredelenie koordinat preobrazovatelej na obekte pri akustiko-emissionnom kontrole," in D. A. Terentev, A. L. Alakritskij, M. U. Rostovcev, Kontrol, Diagnostika, 2007, pp. 31-34.

[7] F. Ciampa and M. Feo, "A new algorithm for acoustic emission localization and flexural group velocity determination in anisotropic structures," Applied Science and Manufacturing, vol. 41, issue 12, pp. 1777-1786, December 2012.

[8] F. Ciampa and M. Feo, A new wavelet based algorithm for impact identification and group velocity determination in composite structures: Proceedings of the 5th European Workshop - Structural Health Monitoring 2010, pp. 1057-1063, June 28 - July 4, Naples, Italy, 2010.

[9] F. Ziegler, "Acoustic emission from Plastic source," Journal of Computational Acoustics, vol. 9, issue 4, pp. 1329-1345, December 2001 . http://dx.doi.org/10.1142/S0218396X01001182

[10] V. E. Vainberg, "Determination of the coordinates of an Acoustic Emission source in two and three dimensional spaces without the aid a computer," The Soviet journal of non-destructive testing, vol. 17, issue 6, pp. 473-477, 1981.

[11] B. Muravin. Acoustic wave propagation and source location. [Online]. http://www.muravin.com/ [Accessed Jan. 15, 2014].

[12] MI 207-80. Metodika opredelenia mestopolozenia razvivausihsa defektov akustiko-emissionnym metodom. Gosstandart. NPO Dalstandart, 1980.

[13] V.V. Kluev. Nerazrusausij kontrol. Spravocnik. Moskva: Masinostroenie, 2003.

[14] R. K. Manindra and A. Tan, "Source location of acoustic emission waves for structural health monitoring of bridges," 2012. [Online]. http://eprints.qut.edu.au/Brisbane [Accessed Jan. 18, 2014].

[15] H. Vallen, "AE Testing Fundamentals, Equipment, Applications", 2002. [Online]. http://www.ndt.net/index.php [Accessed Jan. 28, 2014].

[16] M. G. Baxter, R. Pullin, K. M. Holford and S. L. Evans, "Delta T source location for acoustic emission," Mechanical Systems and Signal Processing, vol. 21, issue 3, April 2007, pp. 1512-1520. http://dx.doi.org/10.1016/j.ymssp.2006.05.003

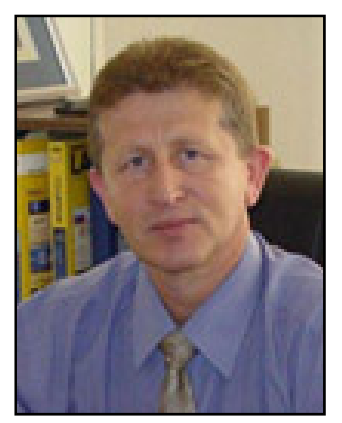

Aleksandrs Urbahs graduated from the Faculty of Mechanical Engineering, Riga Civil Aviation Engineering Institute in 1981. In 1986 he was awarded the Dr.sc.ing. degree by the same faculty. In 1997 he was awarded the Dr.habil.sc.ing. degree by Riga Aviation University. In the period of 1989-1999 - Vice Dean and Dean of the Faculty of Mechanical Engineering, Riga Aviation University. Since 1999 - Full-time Professor at Riga Technical University. In the period of 1999-2012 - Head of the Institute of Transport Vehicle Technologies at Riga Technical University. Since 2012 - Head of the Institute of Aeronautics at Riga Technical University. He holds 19 patents and has published 297 scientific papers. 
His fields of research: aeronautics, nanomaterials, non-destructive methods of control, structural materials, unmanned vehicles, transport systems and logistics.

Address: Institute of Aeronautics, Faculty of Transport and Mechanical Engineering, Riga Technical University, Lomonosova 1A, k-1, Riga, LV1019, Latvia.

Phone: +37167089990, e-mail: Aleksandrs.Urbahs@rtu.lv

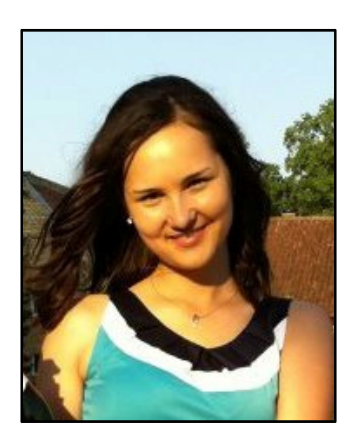

Aija Valberga (ex.Redmane) received a Master's Degree in Transportation Systems Engineering from Riga Technical University in 2011. At the moment she works as a Production Planning Manager and Workshop Production Manager at Volburg Ltd., Electronics Manufacturing Services Company. Her fields of research: lean manufacturing, logistics and transport systems, nondestructive testing.

Address: Institute of Aeronautics, Faculty of Transport and Mechanical Engineering, Riga Technical University, Lomonosova 1A, k-1,

Riga, LV-1019, Latvia.

Phone: +371 67089990

E-mail: aerti@rtu.lv, aija.valberga@gmail.com

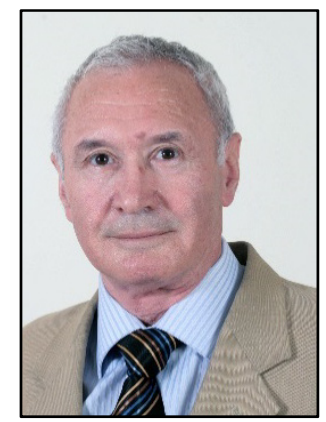

Muharbijs Banovs graduated from Riga Civil Aviation Engineering Institute as a Mechanical Engineer of Aircraft and Engine Maintenance in 1975. In 1979 he was awarded a Doctoral Degree, Faculty of Aircraft Repair and Technology, Riga Civil Aviation Engineering Institute. 1981-1995 - Assistant, Assistant Professor, Professor, Lecturer of Riga Civil Aviation Engineering Institute. 1995-1998 Assistant, Assistant Professor, Professor, Lecturer of Riga Aviation University. Since 1999 - Assistant, Assistant Professor, Professor, Lecturer of Riga Technical University of Institute of Transport Vehicle Technologies. Since 2007 he has been conducting Supreme State Engineering Courses of Improvement of Qualification on Non-destructive Testing.

His fields of research: aeronautics, non-destructive testing.

Address: Institute of Aeronautics, Faculty of Transport and Mechanical Engineering, Riga Technical University, Lomonosova 1A, k-1, Riga, LV1019, Latvia.

Phone: +37167089990

E-mail: Muharbijs.Banovs@rtu.lv

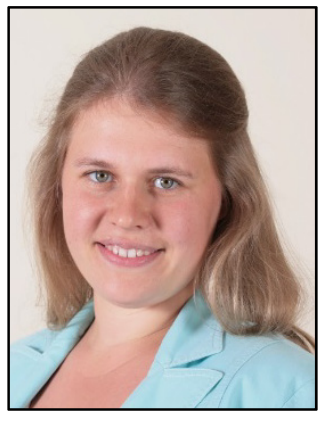

Kristine Carjova has been a Doctoral Student at the Institute of Aeronautics, Riga Technical University since 2011. In 2010 she obtained a degree of Master of Science at the Latvian Maritime Academy. She graduated from the Latvian Maritime Academy and obtained a Specialisation of Engineer-Ship Navigator. Work experience: 2004-2007 - Navigator of Merchant Vessel. 2009-2011 - Captain on ASD tugboat at JSC PKL Flote. Since August 2011 - Researcher at the Institute of Aeronautics, Riga Technical University.

Her fields of research: aeronautics, nanomaterials, non-destructive methods of control, structural materials, unmanned vehicles, transport systems and logistics.

Address: Institute of Aeronautics, Faculty of Transport and Mechanical Engineering, Riga Technical University, Lomonosova 1A, k-1, Riga, LV1019, Latvia.

Phone: +371 67089990

E-mail: Kristine.Carjova@rtu.lv

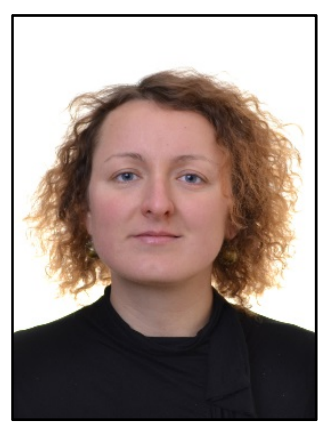

Ilze Stelpa has been a Master Student at the study programme "Transport System Engineering", Riga Technical University since 2012. In 2011 she graduated from the Latvian Maritime Academy and obtained a Specialisation of Engineer-Ship Navigator. Since 2011 she has been a Ship Navigator. From 2008 to 2010 - President of Students' Scientific Council of the Latvian Maritime Academy.

Her fields of research: acoustic emission, liquefied natural gas use, polar water navigation, marine environment protection.

Address: Institute of Aeronautics, Faculty of Transport and Mechanical Engineering, Riga Technical University, Lomonosova 1A, k-1, Riga, LV-1019, Latvia.

Phone: +37167089990

E-mail: Ilze.Stelpa@rtu.lv 
